\title{
REFLEXIONES ACERCA DEL JUICIO LIMÍTROFE DE PERÚ CONTRA CHILE, ANTE LA CORTE INTERNACIONAL DE JUSTICIA
}

\author{
REFLECTIONS ABOUT THE BORDER TRIAL OF PERÚ AGAINST CHILE \\ ON THE INTERNATIONAL COURT OF JUSTICE
}

\section{SAMUEl FERNÁNDEZ ILLANES*}

Se ha escrito y comentado abundantemente y con razón, por ser un tema de actualidad y gran importancia, sobre la demanda presentada por el Perú ante la Corte Internacional de Justicia con sede en La Haya. Una nueva controversia limítrofe que debe hacer frente Chile en los últimos cincuenta años. Una vez más, a nuestro parecer y según todas las declaraciones oficiales, nos asiste plena confianza ya que los títulos y argumentos jurídicos chilenos que avalan nuestra posición, están basados en tratados vigentes y en la costumbre de largos años. Así se ha reiterado luego del primer contacto de las Partes con la Presidencia de la Corte. Y no tendríamos porqué tener dudas.

Entonces no cabe sino esperar una sentencia que los confirme, si acordamos acudir a la Corte.

\section{CONTROVERSIAS PRECEDENTES:}

Sin embargo, si recordamos los diferendos limítrofes con Argentina, sobre la Región Palena-Río Encuentro, en 1966; el conflicto austral en el Canal de Beagle, en 1967; así como el de Laguna del Desierto, en 1991; sus resultados no se limitaron a ratificar enteramente nuestros derechos tal y como los argumentábamos previamente.

En el caso Palena, el arbitraje de Su Majestad Británica tuvo características transaccionales, que debimos aceptar.

Respecto al Canal de Beagle, el fallo de los cinco Jueces ad hoc, elegidos de común

\footnotetext{
* Licenciado en Derecho, Pontificia Universidad Católica de Chile, Profesor de Derecho Internacional Público y Profesor de Relaciones Internacionales, Embajador (R), samuelferi@gmail.com.
}

acuerdo, pertenecientes a la propia Corte Internacional de Justicia, refrendado por el Arbitraje de Su Majestad Británica, aunque fue enteramente favorable a nuestro país, Argentina lo declaró insanablemente nulo. Se debió por tanto, a riesgo de una confrontación bélica, acudir a la mediación papal y finalmente, gracias a una negociación directa, poner fin al litigio. Las tres islas en disputa, quedaron definitivamente para Chile. No así las proyecciones marítimas en la zona austral que nuestro país pretendía antes del conflicto, pues se acordó otra delimitación en un nuevo Tratado de Paz y Amistad (1984).

En cuanto al caso de Laguna del Desierto, algunos territorios importantes defendidos por Chile como propios, pasaron a la Argentina, según el fallo dividido de los tres jueces latinoamericanos elegidos por ambos países, no pertenecientes a la Corte de La Haya, más el juez chileno y el argentino. Fallo de 1994 que debimos acatar al no existir ningún recurso superior, salvo los de revisión o aclaración, que no procedieron.

Estas experiencias demuestran, de manera bastante elocuente, que una vez radicado un pleito ante un tribunal, compuesto por árbitros o jueces internacionales, que se le otorgue competencia, se debe estar a sus resultados. Estos pueden no ser totalmente favorables a solo una de las partes, o pueden determinar una solución transaccional o equitativa, u otra no prevista, más acorde con la evolución y nuevas tendencias del Derecho Internacional aplicable, o según la íntima convicción personal de los jueces. Aunque parezca obvio, depende del Tribunal que conoce del caso y de su sentencia respectiva.

Es sabido de que todo asunto internacional no está sujeto a reglas fijas. Pueden 
igualmente tener incidencia, otros factores, propios de la complejidad e interrelación de las prácticas internacionales.

Por cierto también dependerá de la manera en que se defiendan nuestros derechos y de las personas que intervengan profesionalmente. En este punto sí que no caben comentarios, ya que no hay duda de que estarán a cargo de ello, ahora y durante todo lo que dure el juicio, los más idóneos, tanto nacionales como extranjeros. Constituye la responsabilidad primaria de todo Gobierno Nacional.

\section{EL CASO ENTRE PERÚ Y CHILE:}

Pero volvamos a la demanda del Perú. ¿Acaso se trata de una aventura peruana, sin fundamento ni sentido y por razones no solo relacionadas con los límites marítimos o terrestres ya definitivamente zanjados desde hace largo tiempo? ¿Se demanda únicamente por intentar obtener aunque sea una mínima revisión de las fronteras y de tal manera ampliar, aunque sea en parte, territorios o el mar controlado por Perú? Si así fuere, equivaldría a cualquier pretensión de un propietario de reclamar un trozo del jardín de su vecino, porque se le ocurrió un día de mal humor. Resulta imperioso entonces, además de examinar la pretensión respectiva, conocer a cabalidad, por qué lo hace Perú, cuáles son sus argumentos, sus títulos, sus razonamientos históricos y jurídicos y, en fin, las causas más profundas que lo han impulsado a llevarnos ante la Corte Internacional de Justicia. Buena parte de ello estará contenido en la Memoria que Perú presentará ante el Tribunal antes del veinte de marzo de 2009 y que deberá notificarse a Chile, una vez acordado por los dos países iniciar el juicio ante la Corte Internacional.

Debe enfatizarse que todo lo que obtenga Perú como resultado del juicio, si así fuere, no lo poseía anteriormente. Por lo tanto, en tal caso, alcanzaría un triunfo importante a expensas de Chile. En caso contrario, nada lograría. Chile solo vería ratificados los límites que siempre ha defendido como propios.

Por lo expuesto, sería pertinente evaluar y revisar, en toda su magnitud, si hubo alguna debilidad de nuestra parte, o algo escapó a nuestro control o no se advirtió oportunamente. Por lógica a nadie se le ocurre reclamar lo que no es suyo sin base alguna, y de manera intempestiva, aunque finalmente se declare que no le correspondía tal derecho. ¿Por qué se ha materializado ahora esta demanda luego de tanto tiempo de vigencia de nuestros límites? Por muchos años fueron respetados por una práctica constante, que recién Perú inicia su cuestionamiento en 1986. Estaban y están plenamente amparados en la "Declaración de Zona Marítima" de 1952, y en el "Convenio sobre Zona Especial Fronteriza Marítima” de 1954, ratificados por los dos países; así como en las respectivas Actas de la Comisión Mixta de Límites Chileno-Peruana y la colocación de Hitos y señales en el terreno.

De la misma manera es de suma importancia conocer las razones que Chile tendría, si así finalmente accediera, para dirimir el caso ante la Corte Internacional de Justicia, uno de los medios tradicionales, aunque no el único, de solución judicial y pacífica de controversias. Es lógico plantear esta interrogante, si al menos por parte nuestra, nada queda por resolverse, luego de las Actas de Ejecución posteriores a las fracasadas "Convenciones de Lima" de 1992, que pusieron término a la entrega de las obras en Arica para el servicio del Perú que se encontraban pendientes de ejecución, contenidas en el Tratado de Lima de 1929 y su Protocolo Complementario. Empleo el término "pendientes de ejecución", que me parece más adecuado que el de simple "cláusulas pendientes", el que podría implicar un incumplimiento responsable por Chile de dichos Tratados, cuando en verdad siempre requirieron de consulta al Perú y su aceptación, solo obtenida en las Actas citadas.

Siguiendo este razonamiento, también es pertinente saber, al no existir un acuerdo específico pactado con antelación, por qué se hará uso de la llamada "cláusula opcional" como declaración de voluntad de cada Estado si se llega al juicio contencioso ante la Corte; o si Chile recurrirá a más posibilidades procesales, como las medidas conservativas para asegurar nuestros derechos; o excepciones preliminares, suspendiendo el procedimiento hasta que sean resueltas, con lo que el Tribunal po- 
dría declararse incompetente; u otras que pudieren corresponder. Por ejemplo, solicitar a la propia Corte una Opinión Consultiva, previa a cualquier sometimiento a la jurisdicción del Tribunal y así obtener un pronunciamiento sobre la validez jurídica de la demanda. Seguramente nuestra defensa las está evaluando.

Asimismo, se debe considerar el pleno y fructífero funcionamiento de la Comisión Permanente del Pacífico Sur (CPPS), desde 1952. Los respectivos acuerdos logrados no solo con el Perú, sino con Ecuador y Colombia y analizar si pueden verse cuestionados. Nada lo indica hasta ahora y no se han planteado diferendos limítrofes marítimos entre Perú y Ecuador ni existen aún reformulaciones de los respectivos convenios limítrofes o pesqueros. Entonces, ¿por qué solo se ven afectados los que Perú ratificó con Chile? Los límites marítimos que siguen vigentes para Ecuador ya no lo son para Chile, a juicio peruano. De la misma manera, están en vigor y se aplican sin objeciones nuestros múltiples acuerdos en materia de integración bilateral, tanto física como económica. ¿Existen o no adicionales razones que inspiran el proceder actual del Perú respecto a las fronteras con nuestro país y que no conocemos a cabalidad?

Para nadie es un misterio de que mientras dure este pleito, varios años como sería de esperar (entre cuatro, seis o más), se corre el riesgo de que todos los aspectos de una rica y variada relación vecinal, se vea condicionada o distorsionada, inevitablemente, por el juicio en curso, o más de alguien se aproveche del diferendo para complicar las cosas, incitando ambas poblaciones. Pretender que no existe o dejarlo encapsulado y que discurra de manera autónoma, no es más que un buen deseo. Lo real es que potencialmente incida en nuestras relaciones de país a país mientras subsista. Y todo ello por sobre la voluntad de las respectivas autoridades. Es algo que debemos, responsablemente, tener en consideración.

\section{EVENTUALES IMPLICANCIAS PARA LA REGIÓN Y EL MUNDO:}

Otro punto a meditar y más allá de los argumentos propiamente jurídicos ya conoci- dos, lo constituye la situación regional. De una u otra manera ante un conflicto limítrofe, como ante cualquier otro de características internacionales, nada termina por ser completamente ajeno a los intereses y visiones políticas y a las posiciones de los países. La prensa peruana y chilena, o la del continente e inclusive la de medios internacionales, seguramente tendrá buen cuidado de recordarnos los pormenores del pleito. Estas posibilidades pueden ser todavía más frecuentes en nuestra región, caracterizada por liderazgos muchas veces vehementes y por la volatilidad en las posiciones que compiten por imponerse.

No quiero decir con esto de que los gobiernos regionales estén llamados a intervenir en el asunto. Solo menciono que no sería de extrañar el que se manifiesten posturas, apoyos o expresión de deseos y hasta favoritismos hacia alguna de las partes, por motivos sin relación con el juicio mismo ante la Corte, o como una expresión perfectamente lógica ante una controversia internacional que involucra a dos países relevantes de Sudamérica. En prueba de lo dicho, están las recientes declaraciones de solidaridad del Presidente del Ecuador con nuestro país.

Lo mismo sería válido para toda la comunidad de naciones que está en su derecho de manifestar sus posturas, individuales o en el seno de organismos internacionales.

El sur del continente americano sigue siendo mirado con cierto recelo tanto en Estados Unidos como en Europa, y en otras regiones no se le conoce suficientemente. Tenemos particularidades muy propias, como es natural. Por ejemplo, reaccionamos algo más precipitadamente que como lo hacen en otras áreas. Muchas veces de manera emocional y poco meditada. Las periódicas furias o reconciliaciones producto de calificativos altisonantes entre algunos líderes regionales, no permiten asegurar ni menos proyectar en el tiempo posiciones únicas y definitivas. Estas suelen cambiar con rapidez y no pocas veces dependen del estado de ánimo de la autoridad de turno. Es por ello que, por lo general, no representamos políticas constantes ni alternativas trascendentes para el sistema mundial. Tal vez no sea perjudicial del todo, ya que muy poco de 
lo que sucede en Latinoamérica tiene verdaderamente impacto global. Eso sí, como tampoco tenemos todo resuelto ni estamos exentos de turbulencias de cualquier tipo, en especial si se trata de diferendos fronterizos en los que se cuestionan soberanías nacionales tan caras a nuestro sentir latinoamericano, las posibilidades de confrontación siguen latentes. Así nos perciben, para bien o para mal, y es una realidad que en nada desmerece nuestro valor intrínseco y el pleno derecho que nos asiste a participar e intervenir en los asuntos internacionales.

Latinoamérica muestra hoy en ciertos casos, claras señales de tensión y posiciones políticas antagónicas con riesgos posibles para la plena vigencia democrática y para las instituciones en que se fundamenta. Las cuales son potencialmente explosivas, más por evidenciar ocasionales diferencias insalvables, que por la voluntad de sus pueblos. Basta una mirada somera para constatarlo.

En varios países se intentan experiencias diferentes, las que se confrontan con otras en vigencia. Todo ello facilita la polarización y la búsqueda de apoyos y alianzas, aún fuera de la propia región, lo que provoca reacciones positivas o negativas. Un diferendo limítrofe como el peruano-chileno, no debería estar al resguardo de estas contingencias, por mucho de que se radicara en la Corte de La Haya como un caso jurídico, más aún si se prolonga en el tiempo y las pugnas regionales se profundizan.

Otro factor a considerar, será el signo político, relaciones de amistad, preferencias ideológicas y vínculos personales de los Gobiernos, chileno o peruano, actuales o futuros, mientras dure el juicio ante la Corte, y de manera especial, al momento del fallo. Podrían constituir un elemento relevante respecto a la actitud, regional o mundial, frente al caso y a la solución que alcance. Al momento de la sentencia se harían más patentes las señales y tendencias en Latinoamérica a que aludíamos.

De más está resaltar, que el diferendo y su desenlace será seguido con atención por los países ribereños del Océano Pacífico, por los acuerdos en vigor. También, y de manera prioritaria, estimo que Bolivia tendrá un interés particular en el juicio. En efecto, su aspiración marítima podría verse modificada en las proyecciones oceánicas, en el caso eventual de que los actuales límites se vieren modificados, si se impusiera, aunque sea en parte, la tesis demandada por Perú. En el entendido de que Chile y Bolivia llegaren a algún arreglo al respecto en el futuro, y de obtener Perú tal rectificación, todo derecho hipotético que Bolivia adquiera mediante una salida soberana al Pacífico, se encontraría entonces, no frente a una zona marítima perteneciente a Chile, sino a Perú, en dirección hacia la alta mar. En tal caso, el límite marítimo ya no sería el paralelo terrestre que ha venido rigiendo, sino la bisectriz o parte de ella propugnada en su demanda. Ciertamente habría consecuencias, si se dieran las condiciones antedichas, a pesar de que Perú afirmó que todo acuerdo sobre acceso al mar para Bolivia, sería en aguas chilenas, las que quedarían delimitadas de manera diferente. Por lo tanto, es lógico de que Bolivia no sea un espectador más de la controversia ante la Corte y la siga muy de cerca. Asimismo, mientras dure y no se conozca la sentencia final, todo arreglo marítimo que se pactare entre Chile y Bolivia, si se diere el caso de que tuviere incidencia en el área en disputa, no estaría en condiciones de ser definitivo ya que abarcaría zonas sometidas a un litigio jurídico pendiente.

Se puede argumentar que lo planteado no es más que otra especulación, pero no por ello deja de tener repercusiones para las relaciones chileno-bolivianas. Probablemente estaríamos en presencia de consecuencias adicionales no deseadas, mientras esté pendiente la demanda peruana. A menos de que hubieren sido imaginadas como una manera incidental de condicionar todo posible proyecto de tratativa, actual o futura con Bolivia y hasta que la Corte emita su sentencia. Al respecto, podemos recordar que las negociaciones en 1975 para un corredor boliviano al sur de la Línea de la Concordia chileno-peruana, al ser consultado Perú, como correspondiera en virtud del Tratado de 1929, propuso que al llegar al mar, se crearan tres zonas soberanas, cada una para los tres países y con su vértice en la cuidad de Arica. Propuesta que canceló las nego- 
ciaciones al ser rechazado por Chile. La respuesta de Perú, en definitiva, hizo inviable el corredor para Bolivia, a sabiendas de que sería inaceptable para Chile.

\section{LA CORTE:}

Mencionábamos anteriormente lo que representa dentro del sistema mundial vigente la Corte Internacional de Justicia donde se radicaría el juicio. Será, si hay acuerdo de otorgarle competencia, la que dictará su fallo definitivo e inapelable. Es el órgano judicial principal del sistema de las Naciones Unidas cuyos miembros son, automáticamente partes del Estatuto de la Corte por el solo hecho de pertenecer a Organización o por adherir al Estatuto. Sin embargo, cada Estado es libre de reconocer su competencia que es facultativa y solo para el juicio de que se trate, al aceptarse la cláusula opcional ya citada. A menos que se acuerde anticipadamente su jurisdicción entre las partes de un tratado, bilateral o multilateral.

Con sede en la ciudad de La Haya (Países Bajos), la Corte (CIJ), la componen 15 jueces, que actúan como magistrados independientes, sin tener en cuenta su nacionalidad; que gocen de alta consideración moral; y que sean jurisconsultos de reconocida competencia en materia de Derecho Internacional. Asimismo, los electores tendrán en cuenta no solo que las personas que haya de elegirse reúnan individualmente las condiciones requeridas, sino también, que en el conjunto estén representadas las grandes civilizaciones y los principales sistemas jurídicos del mundo. Así lo dispone el Estatuto.

Los requisitos antedichos nos llevan a algunos comentarios.

De ninguna manera se pone en duda la capacidad e independencia de la Corte. Sin embargo, por tratarse de uno de los Órganos principales de las Naciones Unidas no podemos desconocer el carácter eminentemente político de la Organización, derivado de su calidad de ser el más relevante foro internacional. A diario todos sus debates, competencias, recomendaciones, decisiones y resoluciones, se discuten y finalmente se adoptan por criterios eminentemente políticos, según las respectivas posiciones de los países. Como es natural, estas obedecen a convicciones ideológicas o de otra índole de conformidad a la acción y objetivos de la política exterior de cada uno de sus miembros.

La disposición que señala el que no se tendrá en cuenta la nacionalidad del juez, en la práctica, no es posible aplicarla taxativamente, pues todos los cargos de elección en las Naciones Unidas, están sujetos a la regla de la representación geográfica equitativa y a los cupos acordados previamente para cada Grupo Regional. Es así como al grupo de Latinoamérica y del Caribe le corresponde elegir solo a dos magistrados.

En cuanto a que gocen de alta consideración moral y que sean de reconocida competencia jurídica en el Derecho Internacional, no se cuestiona. No existen candidaturas de personas incompetentes. Si excepcionalmente así ocurriera, simplemente no se les elige.

Otro requisito que hoy resulta un tanto inaplicable, en particular en un mundo globalizado, es la representación que se pretende de las grandes civilizaciones. También podría considerarse obsoleto el que la Corte represente los principales sistemas jurídicos del mundo, pues los jueces se eligen de acuerdo a los mencionados cupos regionales que se aplican a toda elección en el Organismo y donde están incorporados, sin excepción, los Estados Miembros que son parte del Estatuto. A pesar de ello, estimo que es un punto que podría resurgir con mayor énfasis, dado que la juridicidad internacional no es todo lo uniforme en la actualidad, de lo que fuera a la creación de las Naciones Unidas.

En ciertos casos se puede apreciar el que algunos países o grupo de países emergentes como potencias mundiales, han comenzado a reivindicar el valor de representar civilizaciones muy antiguas y poderosas, muchas anteriores al gran sistema jurídico de raíz occidental que fuera el referente que se tuvo en cuenta al consignar esta disposición. Muchos de ellos con tradiciones, normas, principios y prácticas propias. Así podríamos tener en consideración la existencia de sistemas legales en el mundo árabe, judío, indio, pacífico-insular, chino, japonés, 
en el Asia y otros, que rigen todavía internamente en vastas regiones del mundo, y que en algunos casos han retomado mayor fuerza y vigencia, de la mano con el renacimiento de corrientes filosóficas, religiosas y de costumbres históricas que apreciamos como tendencia creciente. Algunos respetados juristas árabes, por ejemplo, hace tiempo argumentan que el sistema jurídico occidental les fue impuesto, sin su participación efectiva ya que ni siquiera eran Estados independientes al firmarse la Carta y el Estatuto de la CIJ, en 1945. Han desarrollado esta tesis, entre otros, el que fuera juez y presidente de la Corte Internacional y posteriormente canciller de Argelia, el distinguido profesor Mohammed Bedjaoui.

Otros aducen razones doctrinarias o la exclusión de minorías para oponerse al sistema occidental predominante. En fin, si bien no hemos llegado a la materialización de estos cuestionamientos, no es extemporáneo enunciarlos ya que pueden presentarse en el futuro. Se puede recordar al respecto, que en el proceso de reformas de las Naciones Unidas que todavía se discute, el Grupo Árabe ha argumentado que debería contar con un miembro permanente en el Consejo de Seguridad reformado, pues representan una cultura individual, milenaria e independiente de las demás.

Para profundizar algo más estos razonamientos, conviene repasar someramente, cómo se compone la Corte Internacional de Justicia.

Los jueces son elegidos en votaciones secretas, simultáneas y por separado tanto en el Consejo de Seguridad como en la Asamblea General de las Naciones Unidas. Sus resultados no se dan a conocer hasta que cada órgano complete su ronda de votación. Esto en teoría, pues de una u otra manera siempre se filtran. Cabe tener presente que en el Consejo de Seguridad no se aplica el "veto". Resultan electos quienes alcancen, antes que los demás, la mayoría absoluta de votos dentro de las vacantes reservadas para cada Grupo Regional. Se eligen por parcialidades y una vez que cada juez complete su período de nueve años en el cargo, con posibilidad de ser reelegido. Ello representa en la práctica que la Corte se renueva de tiempo en tiempo, por lo general en grupos de a cinco jueces en cada elección.
Destaco este hecho, pues significa que si el juicio con Perú queda radicado en la Corte el presente año 2008, y no hay un fallo definitivo hasta dentro de cuatro, seis o más años, en el tiempo intermedio la Corte renovará su composición al elegir o reelegir nuevos integrantes. Es decir, no todos los magistrados que comiencen a conocer de la causa serán llamados a dictar la sentencia. Un antecedente que puede tener consecuencias en las decisiones jurídicas de la Corte, ya que cada juez, como es natural, puede tener su propia visión del caso ajustada a sus convicciones legales y donde no es posible excluir totalmente, pese a la imparcialidad a que está obligado a actuar el Tribunal, las naturales simpatías que le pudieren inspirar cada una de las partes y sus argumentaciones.

No es una afirmación sin fundamento. El propio Estatuto de la Corte en su conocido Artículo 38, el cual señala que su función es decidir conforme al Derecho Internacional las controversias que le sean sometidas, para luego enumerar en cuatro párrafos lo que la Corte deberá aplicar y que los tratadistas coinciden en señalar como fuentes del mismo Derecho (convenciones, costumbre, principios generales, y decisiones judiciales y doctrinas); expresa que esta disposición no restringe la facultad de la Corte para decidir un litigio ex aequo et bono, es decir, conforme a la equidad, si las partes así lo convinieren. No sería aplicable al juicio chileno-peruano, ya que no corresponde, al menos por nuestra parte, pues está fundamentada en los variados acuerdos vigentes. Pero resulta revelador de que la íntima convicción de los jueces, pueden tener incidencia, y más aún aplicarse estatutariamente, cuando los litigantes así lo pactan. En todo caso, el mencionado artículo 38 del Estatuto, obliga a la Corte a considerar como fuente de sus fallos, a falta de aquellos precedentes, las doctrinas de los publicistas de mayor competencia de las distintas naciones, como medio auxiliar para la determinación de las reglas de derecho. Entre las cuales pueden estar lo que cada juez haya postulado como tratadista antes de ser elegido para integrar el Tribunal.

Otro tanto podría suceder si la Corte no encontrara solo pertinentes las razones jurídicas invocadas por las Partes, o si estimara 
que el derecho aplicable no está vigente o no es suficientemente claro, o no es unánimemente aceptado o se encuentra en plena evolución o es cuestionado por buena parte de la comunidad de naciones. Se trata ciertamente de casos excepcionales, frente a los cuales la Corte se vería obligada a fallar sobre la base de la equidad u otros criterios, a falta de normas legales aplicables. También podría ante tal disyuntiva, declararse incompetente para no sentar una jurisprudencia contraria a derecho y de aplicación universal. Es evidente de que estos ejemplos no tienen relación con el caso analizado, pero vale la pena consignarlo, pues una vez más es indicativo de que la Corte es soberana para apreciar las razones jurídicas y de hecho de los contendores, así como para, dentro de las normas a que debe regirse de acuerdo a su Estatuto y a su propia jurisprudencia, aplicar el derecho que servirá de fundamento a su sentencia.

Menciono este punto ya que, según se conoce, Perú centraría en lo medular su aspiración, en que no hay límites marítimos definitivos con Chile, pues tanto la tripartita Declaración de Zona Marítima de 1952 (Declaración de Santiago) y el Convenio sobre Zona Especial Fronteriza Marítima de 1954, serían solo acuerdos en materia pesquera. Aquí estamos en presencia del Derecho del Mar, el que todavía presenta ciertos cuestionamientos para algunos países, a pesar de la Convención de 1982 (CONVEMAR) y de los numerosos acuerdos sobre pesquerías vigentes en distintas partes de mundo. Ambas disciplinas especializadas tienen, en ocasiones, partidarios, que defienden y protegen sus áreas marinas, y en otros casos, detractores que las impugnan para continuar con las actividades extractivas. Ello es posible advertirlo en el seno de organismos como la FAO, competente para los asuntos pesqueros internacionales $y$ en donde es usual el que inclusive, jurídicamente, se argumente que las normas adoptadas y aceptadas en el derecho del mar, tanto las consuetudinarias como particularmente las consignadas en la Convención de Montego Bay, están en proceso de evolución y de aceptación universal.

Ello es de usual ocurrencia dado que las delimitaciones marítimas siguen constituyen- do uno de los puntos más debatidos internacionalmente, y en especial cuando son proyectadas hacia la Alta Mar, teniendo como base límites terrestres, aguas interiores, mar territorial, zonas contiguas o zonas económicas exclusivas, que se superponen o son impugnadas por algún otro Estado ribereño. Podemos mencionar el conocido caso de la caza de ballenas, cuyos acuerdos de protección ciertos países no respetan. Lo señalo además como ejemplo pertinente, en relación a que algunas normas aplicables al posible juicio que analizamos, pueden tener interpretaciones diferentes y hasta contrarias, dependiendo de las particularidades del área geográfica y de las posiciones jurídicas de quienes pudieren considerarse afectados por toda jurisprudencia al respecto que emanare de la Corte.

Lo anterior, podría invocarse o bien ser materia de análisis en los países y por los juristas no coincidentes con el Derecho del Mar y las reglas sobre pesca que rigen en el continente sudamericano o que defienden Chile y Perú en sus respectivas posiciones. Cabe la posibilidad, asimismo, de que se incorporen a las razones jurídicas que se tendrán a la vista en el juicio, sobre todo si una de las Partes basare en ellas algún aspecto de sus argumentos. Cabe recordar que Chile es Parte de la Convención del Mar desde 1997. Perú no la ha ratificado.

Las polémicas que origina el nuevo Derecho del Mar o los asuntos de pesca internacional pudieren ser, además, tenidas en consideración por algunos miembros de la Corte, si su convicción de que tanto lo defendido por Perú como por Chile en sus proyecciones marítimas (para el Perú como simples acuerdos en materia pesquera, o para Chile como límites marítimos definitivos), no son unánimemente aceptados internacionalmente y en todas la regiones. Por lo tanto, al no contarse con un derecho uniforme aplicable y existir posiciones encontradas, la Corte podría optar por dar una interpretación diferente a las invocadas a objeto de no sentar una jurisprudencia que sería constitutiva de fuente jurídica auxiliar para todos los países y para todos los casos.

Nuevamente estoy poniéndome en una situación meramente especulativa, ya que lo natural es que la Corte se pronuncie justamen- 
te en mérito al proceso y a las reclamaciones jurídicas de las partes en litigio. Sin embargo, como este análisis tiene precisamente por objeto el reflexionar sobre aquellos posibles aspectos no tradicionales o inesperados relativos al tema, me he referido a ello teniendo en cuenta la experiencia observada en organismos internacionales y las diferentes interpretaciones que surgen toda vez que se abordan problemas de delimitación relacionados con el Derecho del Mar o la pesca internacional.

Lo dicho apunta a que por encima de las reglas jurídicas, y como en todo caso judicial, en la práctica no solo se evalúan y aplican exclusivamente los méritos legales de manera uniforme, sino que también es posible que incidan, de una u otra manera, elementos complementarios, como los descritos y también las posiciones doctrinarias que cada magistrado haya defendido a lo largo de una vida dedicada al Derecho Internacional, o las convicciones personales que cada juez se hubiere formado sobre lo planteado por las partes. La Corte no es un ente impersonal. Está compuesta por juristas, ciertamente de un nivel superior, pero que no son meros autómatas al emitir un fallo.

\section{LA ELECCION DE LOS JUECES:}

Otro antecedente que también se debe considerar es cómo se originan las candidaturas y el procedimiento para elegir los miembros de la Corte Internacional de Justicia. A la actual Corte se le considera la heredera de la antigua Corte Permanente de Justicia Internacional creada en tiempos de la Sociedad de las Naciones, por lo tanto, se conservó el antiguo procedimiento electoral en el cual los Grupos Nacionales pertenecientes a la Corte Permanente de Arbitraje nominan sus postulantes, que pueden ser no más de uno de su misma nacionalidad, o de otra nacionalidad al que patrocinan y le brindan su apoyo. Es muy usual el que, por razones de simpatía política, o cualquier otra, uno o varios Grupos Nacionales apoyen una candidatura. Además de constituir el procedimiento a seguir, es una manera bastante clara de conocer públicamente los apoyos con que cada candidato cuenta antes de la elección.
Si bien es de las poquísimas normas vigentes desde la Sociedad de las Naciones, tiene perfecto sentido, desde el momento en que el objetivo principal es la preservación del Derecho Internacional y de la jurisprudencia emanada de la antigua Corte, mediante la continuidad institucional.

Se entiende que los Grupos Nacionales eligen sus preferencias de conformidad a los méritos profesionales de los candidatos y en virtud de ellos los proponen. Sin embargo, quien en definitiva vota y decide es el Gobierno de cada país a través de sus representantes ante la Asamblea General y el Consejo de Seguridad. Es por lo tanto una decisión política más, dentro de las habituales en la Organización. Me permito insistir en este punto, para que quede en evidencia que inclusive en la elección de los jueces de la Corte, juegan elementos no estrictamente jurídicos a la hora de elegir los postulantes.

Por lo tanto, y como en toda votación en los organismos internacionales, las candidaturas se negocian, acuerdan u otorgan, mediante una variada gama de apoyos simples o recíprocos, entre postulaciones equivalentes en importancia. Pueden ser simples, como una demostración de la amistad entre países, delegaciones y hasta delegados, si convencen a su respectivo Gobierno. O en retribución a otros apoyos similares recibidos con anterioridad.

Pueden igualmente tratarse de los tan comunes AAR, o acuerdos de apoyo recíproco entre postulaciones de similar trascendencia. Por ejemplo, un voto favorable a la Corte puede ser reciprocado por un voto para el Consejo de Seguridad, u otro órgano principal. También pueden ser apoyos de dos o hasta tres candidaturas por una, según los casos, y para primeras, segundas o más rondas de votaciones. En fin, caben múltiples variantes. Es usual de que estos compromisos se comuniquen por escrito por Notas Diplomáticas, para que así queden formalizados; sin dejar de existir casos aislados y poco éticos de apoyos comprometidos y finalmente cambiados al momento de votar al amparo del sufragio secreto. Si se sospecha o descubre tal irregularidad, la confianza quedaría irremediablemente dañada. Todo ello es demostrativo de que se ejerce una 
decisión plenamente política, lo que no debe extrañar dentro de las prácticas de una Organización de tal naturaleza.

Las elecciones de los jueces de la CIJ, por cierto, no están ajenas a estas contingencias, por lo que tampoco resultaría raro que cada juez elegido o su respectivo Gobierno, conozca perfectamente quienes lo apoyaron, o no lo hicieron, tanto como Grupo Nacional o como país. Es un tema delicado, ya que ello no debería tener consecuencia alguna al momento de emitir una sentencia pues la Corte es un órgano eminentemente jurídico e independiente y no hay que poner en duda su funcionamiento. No obstante, desde el momento en que para ser elegido o reelegido priman consideraciones foráneas a las solas capacidades jurídicas de los candidatos, no se pueden descartar de plano, las naturales reacciones y sentimientos de los interesados, o de las autoridades del país al que pertenecieren. El solo hecho de ser juez de la Corte no los exime del sistema político aplicado a su elección. A mayor abundamiento, el artículo 56 del Estatuto expresa que el fallo será motivado, y que mencionará los nombres de los magistrados que hayan tomado parte en él.

Pongámoslo de manera más clara. ¿Reelegiría un país perjudicado al mismo juez si considerara que su fallo le fue contrario o injusto? ¿Votaría un país por un candidato que abiertamente sostiene una posición académica opuesta? ¿Daría su apoyo a esa postulación el respectivo Grupo Nacional? Resulta lógico de que un país que tiene un juicio pendiente ante la Corte vote por el candidato del país que respalda su postura, o le es afín, o por el magistrado que coincida con sus argumentos, según se conozca por su trayectoria, publicaciones u opiniones jurídicas. Lo mismo sería válido para el Grupo Nacional al momento de elegir a quién propondrá como candidato o a quién otorga su apoyo. Entramos aquí en consideraciones subjetivas, pero no por ello totalmente alejadas de la realidad. Y sería pertinente el que se tuvieran en consideración tanto por Perú como por Chile, cuando corresponda renovar algunos miembros de la Corte Internacional de Justicia.
La actual Corte Internacional de Justicia la integran quince jueces que pertenecen a las siguientes nacionalidades: Reino Unido (presidente), Jordania (vicepresidente), Alemania, China, Eslovaquia, Estados Unidos, Rusia, Francia, Japón, Madagascar, México, Marruecos, Nueva Zelanda, Sierra Leona y Venezuela.

Por lo general, todos los jueces son personalidades conocidas no solo en el ámbito del Derecho Internacional o en la diplomacia de sus respectivos países, sino que muy especialmente, dentro del sistema internacional y las propias Naciones Unidas. La práctica más difundida es la de efectuar una verdadera carrera dentro de la Organización. Esta se inicia, usualmente, en la Sexta Comisión (Asuntos Jurídicos) de la Asamblea General. Encontramos en la actual Corte, varios que han sido destacados delegados o han presidido la Comisión. Luego, dicha carrera continúa mediante la elección a la Comisión de Derecho Internacional (CDI) de Ginebra, la que es considerada como la antesala de la Corte, para luego culminar en ella. Por cierto no hay reglas fijas, $y$ se pueden encontrar connotados magistrados en sus países de origen y hasta ex cancilleres, políticos o embajadores. Tampoco es una carrera fácil y los países se esfuerzan por preparar y promover sus candidatos por años. Las elecciones son sumamente competitivas y necesitan recursos financieros, humanos y diplomáticos de consideración.

Chile ha contado solo con un juez en la Corte Internacional de Justicia, desde su creación. El destacado jurista y profesor, don Alejandro Álvarez (entre 1945-1954). Hubo otra postulación que no prosperó, en 1996. En la Comisión de Derecho Internacional, por su parte, Chile logró la elección de solo dos importantes profesionales, don Fernando Albónico Valenzuela y don Edmundo Vargas Carreño. Resulta poco explicable cómo un país tan apegado a la legalidad y que cuenta con grandes especialistas en Derecho Internacional, además de ser participativo en los Organismos Internacionales, no haya priorizado este campo. Sobre todo si se tiene en cuenta que, como lo demuestran los hechos, nuestros diferendos limítrofes, por desgracia son 
potencialmente recurrentes y por lo general de carácter jurídico, y pueden concluir en la Corte. Tal vez la falta de la debida continuidad en la representación ante los órganos jurídicos que facilitarían la elección a la Corte, por razones ajenas a sus méritos profesionales o por vaivenes políticos, no ha posibilitado contar con los mismos delegados por el tiempo necesario para ganar posiciones hasta ser elegido en la Corte.

No se trata de una aseveración antojadiza y tampoco dirigida hacia una determinada autoridad, ya que la situación se prolonga desde hace más de cincuenta años, y justamente cuando más diferendos lo habrían requerido. Según el Estatuto, si se contara con un juez chileno en la Corte, y la contraparte no tuviere uno de su nacionalidad, esta podría acudir al nombramiento de un juez ad hoc, o viceversa si fuere Chile el que careciere. A lo que me refiero es al conocimiento interno y a cabalidad del sistema de la Corte, sus procedimientos, sus reacciones, sus preferencias, sus sentencias y fundamentos, sus modalidades, el perfil de sus integrantes, las posiciones dominantes, y todo aquello que facilita la convivencia y la relación entre colegas de un tribunal colegiado y que pudiere contribuir a la óptima defensa de nuestras causas, a prestigiar los juristas nacionales, o a la más conveniente elección de los agentes y abogados extranjeros que asuman nuestra representación. Ello, pues es necesario recordar que ante la Corte solo se litiga en idioma inglés o francés. Pertenecer a la Corte es algo sumamente codiciado, y en que normalmente son electos jueces nacionales de los cinco Miembros Permanentes del Consejo de Seguridad.

De más está decir el que estamos ciertos de que nuestras autoridades responsables, o a las que pudiere corresponderle en futuros Gobiernos, si el Juicio abarcare por su duración más de dos administraciones, sabrán tener en cuenta estos y muchos otros aspectos colaterales que pudieren tener alguna relación, positiva o negativa, en relación al diferendo con Perú ante la Corte. Nada es superfluo y nada es irrelevante cuando se trata de la defensa de nuestros límites. Hasta los detalles más mínimos son potencialmente dignos de ser considerados, en particular si solo habrá una sentencia y esta será definitiva e inapelable.

Es así como también y de manera determinante, no solo la jurisprudencia sobre casos relacionados emitida por la Corte jugará un papel trascendente en el fallo. Sino, como se mencionara anteriormente, las posiciones jurídicas sostenidas por cada juez, tanto en su calidad de tal, como en su trayectoria académica y profesional. Son antecedentes que con seguridad están siendo detalladamente analizados y evaluados por nuestros agentes, defensores y asesores. Resulta lógico, pues además de los Tratados, Acuerdos o Convenciones suscritos con Perú y que constituyen la base jurídica esencial de nuestra posición, esta debiera además, ser respaldada por las normas de Derecho Internacional, general o especializado, que correspondan, así como las demás fuentes ya mencionadas, a las que la Corte debe ajustar su sentencia.

\section{CONCLUSIÓN:}

He procurado reflexionar de manera abierta y posiblemente poco convencional sobre nuestro caso con Perú y la Corte Internacional de Justicia que podría llegar a conocerlo. Espero haber llamado la atención sobre las múltiples variantes y elementos no propiamente jurídicos o normativos y hasta imponderables, que podrían tener alguna incidencia en este pleito trascendente. Cuando el Derecho pareciere favorecer de manera más evidente a solo una de las partes en un litigio de esta naturaleza, es el momento en que otras consideraciones, ajenas al juicio mismo, podrían entrar en juego. De otra manera, acudir a la Corte se transformaría en un recurso de mero trámite para ratificar el derecho predominante; o tal vez estéril y hasta perjudicial para quien lo intenta sin fundamentos categóricos. Es un ejercicio largo, costoso y de innegables repercusiones para las partes entre sí y para toda la comunidad de naciones, como todo asunto internacional. A ningún país se le ocurre inventar un diferendo limítrofe solo por ver si obtiene algo, aunque sea mínimo, que no tenía. Sería una aventura altamente riesgosa, en lo interno como en lo 
externo. Son decisiones que se analizan pormenorizadamente y en profundidad, sobre todo si existe un verdadero afán de solucionar pacíficamente y por los medios jurídicos apropiados, tal controversia.

De la misma manera que los países involucrados quedarían entregados a la decisión, como en este caso, del más importante Tribunal Internacional de las Naciones Unidas, igualmente la comunidad internacional deberá respetar su fallo y no intervenir en el desarrollo del proceso, respetando escrupulosamente la decisión que la Corte adopte de manera en- teramente autónoma. $\mathrm{Al}$ propio Organismo y en definitiva al Consejo de Seguridad le corresponde velar por ello. Todo lo cual no significa que en un mundo interrelacionado, competitivo, politizado, donde tantos intereses $y$ posiciones confluyen en las relaciones internacionales, un juicio como el que nos referimos, esté enteramente al resguardo de esos mismos intereses y posiciones. Creerlo así sería desconocer la realidad que nos rodea. De ahí estas reflexiones, que espero sean evaluadas no como certezas, sino como probabilidades que también vale la pena considerar. 